\title{
Spinal anesthesia for muscle biopsy in an infant with a suspected neuromuscular disorder: a case report
}

\author{
Yoshiaki Ishida ${ }^{1,2^{*}}$, Masato Morita ${ }^{2}$, Takahisa Sasaki ${ }^{2}$ and Akiko Taniguchi $^{2}$
}

\begin{abstract}
Background: Neuromuscular disorders (NMDs) occur in different forms and are generally diagnosed using muscle biopsy. Among the available anesthetic management options for infants with a suspected NMD are general anesthesia (GA) and regional anesthesia (RA), including spinal anesthesia (SA). Anesthesia selection is often challenging from the point of potential airway risks and anesthetic drug-related complications.

Case presentation: A 6-month-old male infant repeatedly underwent endotracheal intubation and extubation after birth because of respiratory muscle weakness and copious secretions. He was suspected of having NMD and was scheduled for muscle biopsy. His generalized hypotonia and decreased respiratory function presented a potentially difficult airway and complicated the selection of an appropriate anesthetic method. We selected SA and dexmedetomidine, which are safe for infants.

Conclusion: We report the successful and effective anesthetic management of SA and dexmedetomidine in an infant with a suspected NMD.
\end{abstract}

Keywords: Neuromuscular disorder, Muscle biopsy, Spinal anesthesia, Dexmedetomidine, Infant, Regional anesthesia

\section{Background}

Neuromuscular disorders (NMDs) occur in different forms, and muscle biopsy is often required for differential diagnosis and further treatment [1]. Although general anesthesia (GA) has been predominantly performed in infants undergoing muscle biopsy, it may trigger respiratory complications, particularly in infants with decreased respiratory function due to NMD. Spinal anesthesia (SA) has been safely performed in infants [2-5] and should be an option for patients with respiratory complications. We report SA under sedation with dexmedetomidine in an infant with generalized hypotonia and decreased respiratory function undergoing muscle biopsy. Written informed

\footnotetext{
* Correspondence: cogito_ergo_sum_yoshiaki@yahoo.co.jp

'Department of Anesthesiology, Seirei Hamamatsu General Hospital, 2-12-12 Sumiyoshi, Naka-ku, Hamamatsu-shi, Shizuoka 430-8558, Japan

${ }^{2}$ Department of Anesthesiology, Anjo Kosei Hospital, 28 Higashihirokute, Anjo-cho, Anjo-shi, Aichi 446-8602, Japan
}

consent to publish this case report was obtained from the patient's parent.

\section{Case presentation}

A 6-month-old male infant (weight, $4.4 \mathrm{~kg}$; height, 60 $\mathrm{cm}$ ) was born at $370 / 7$ weeks of gestation with a birth weight of $2144 \mathrm{~g}$. The patient's Apgar scores were 3 and 5 at 1 and $5 \mathrm{~min}$, respectively. Endotracheal intubation was performed immediately after birth by the attending neonatologist because of generalized hypotonia and insufficient respiratory function. Since he was diagnosed with neonatal asphyxia, therapeutic hypothermia was also started. Once his respiratory status stabilized, extubation was successfully performed. However, 5 days later, respiratory muscle weakness led to copious secretions resulting in pulmonary aspiration and airway obstruction, which required endotracheal reintubation. Successful extubation was finally achieved 14 days after birth. He required nocturnal continuous positive airway

\section{Springer Open}

(c) The Author(s). 2020 Open Access This article is licensed under a Creative Commons Attribution 4.0 International License, which permits use, sharing, adaptation, distribution and reproduction in any medium or format, as long as you give appropriate credit to the original author(s) and the source, provide a link to the Creative Commons licence, and indicate if changes were made. The images or other third party material in this article are included in the article's Creative Commons licence, unless indicated otherwise in a credit line to the material. If material is not included in the article's Creative Commons licence and your intended use is not permitted by statutory regulation or exceeds the permitted use, you will need to obtain permission directly from the copyright holder. To view a copy of this licence, visit http://creativecommons.org/licenses/by/4.0/. 
pressure therapy due to respiratory muscle weakness. His physical findings, such as severe hypotonia, mild arthrogryposis, and absent deep tendon reflexes informed a suspected diagnosis of NMD. To confirm this diagnosis, the attending neonatologist performed a nerve conduction velocity test, magnetic resonance imaging, and electroencephalogram, and scheduled the patient for a muscle biopsy 193 days after birth. Fortunately, the patient did not have complications such as cardiovascular disease. We decided to combine SA with dexmedetomidine because of the potential airway risk and possible anesthetic drug-related complications faced.

An intravenous catheter was inserted into the back of his hand before entering the operating room. His blood pressure was noninvasively monitored, along with electrocardiography, pulse oximetry, and continual skin temperature monitoring in the operating room. Dexmedetomidine was administered at $0.5 \mu \mathrm{g} / \mathrm{kg}$ for $10 \mathrm{~min}(3 \mu \mathrm{g} / \mathrm{kg} / \mathrm{h})$, followed by $0.7 \mu \mathrm{g} / \mathrm{kg} / \mathrm{h}$ throughout surgery. During bolus administration, we also administered fentanyl $5 \mu \mathrm{g}$ for analgesia and atropine $0.05 \mathrm{mg}$. Lumbar puncture was performed using a midline approach at the L4-L5 intervertebral space with a 25 -gage cutting needle $(25 \mathrm{~mm})$ in the left lateral decubitus position because the biopsy was to be collected from the left quadriceps muscle. We slowly administered $0.18 \mathrm{~mL} / \mathrm{kg}(0.9 \mathrm{mg} / \mathrm{kg})$ of $0.5 \%$ hyperbaric bupivacaine.

Approximately $2 \mathrm{~min}$ after spinal injection, the patient was unable to move his leg and hip. Three minutes later, the sympathetic nerve block was recorded at the T11 level by loss of the pilomotor reflex. Then, the table was tilted to a reverse Trendelenburg position to avoid further cephalad spread. Anesthesia was maintained using only dexmedetomidine. For postoperative analgesia, we asked the surgeons to infiltrate the wound with $3 \mathrm{~mL}$ of $0.2 \%$ ropivacaine at the time of closure. He was comfortable and breathed spontaneously without additional oxygen and had stable blood pressure, pulse, and oxygen saturation throughout the 38-min surgery. Sensory and motor function gradually recovered and returned to the preoperative level at $3 \mathrm{~h}$ after surgery. About 2 weeks later, he was histopathologically diagnosed with myotubular myopathy.

\section{Discussion}

NMD takes different forms and is categorized into various groups, such as $\mathrm{M}$ (myopathy and muscular dystrophy) and MM (mitochondrial or metabolic myopathy) [1]. A quadriceps muscle biopsy is needed to diagnose NMD, and immobilization of the lower body is required to safely perform the procedure. Anesthetic methods for biopsy include GA and regional anesthesia (RA), which includes SA. In our past experience, local infiltration anesthesia at the surgical site with sedation failed to provide adequate analgesia, and GA with volatile agents was required to prevent body movement. In this case, we combined SA under sedation with dexmedetomidine instead of using GA.

SA is generally considered to be a safe technique for children with a high success rate [2-7]. Because of the relatively large subarachnoid space and cerebrospinal fluid volume in infants compared with adults [2, 3], an anesthesiologist skilled in adult SA can easily perform it in children, as shown by lumbar puncture for children performed by pediatrician trainees. Preservative-free bupivacaine $0.5 \%, 0.2 \mathrm{~mL} / \mathrm{kg}(1 \mathrm{mg} / \mathrm{kg})$ is usually used and the duration of analgesic effect is $70-80 \mathrm{~min}$ [2]. Complications such as neurological injury and an unintentional increase in the spinal block level are extremely rare [2-5]. Moreover, in infants with a suspected NMD, RA, especially SA, rarely causes malignant hyperthermia and rhabdomyolysis, and should be used whenever possible $[8$, 9].

For pediatric SA, infants sometimes require analgesia and sedation in order to prevent any untoward movements during lumbar puncture [4]. We selected dexmedetomidine because it provides fast-onset sedation that parallels natural sleep, with minimal respiratory depression. Dexmedetomidine exhibits neuroprotective effects, has no known active or toxic metabolites, and has been used safely in young children [10]. Our patient achieved good analgesia and sedation with a combination of SA and dexmedetomidine during surgery.

GA should be avoided in patients with a suspected NMD because of the potential problems in securing the airway. Our patient required endotracheal intubation for pulmonary aspiration and airway obstruction due to respiratory muscle weakness and copious secretions before anesthesia. Extubation might have been difficult after GA. Unfortunately, his respiratory status was so poor that he needed a tracheostomy 2 months after this surgery. Additionally, in high-risk infants, GA has a higher incidence of postoperative apnea than SA, resulting in the risk of respiratory complications and the need for postoperative mechanical ventilation [11]. Furthermore, because GA often requires the use of volatile anesthetics and propofol, we must also be wary of rare anesthetic complications. Volatile anesthetics may induce acute rhabdomyolysis, malignant hyperthermia, and/or cardiac arrest, while propofol administration may cause acute metabolic acidosis and cardiac dysfunction in patients with a suspected NMD, including MM $[1,8]$.

In summary, we achieved successful and effective anesthetic management with SA and dexmedetomidine in an infant with a suspected NMD. We believe that SA is effective anesthesia because it minimizes potential airway risk in infants with a suspected NMD. Additionally, dexmedetomidine provides good sedation with minimal respiratory depression during SA. Further reports are needed to assess the feasibility and safety of combining SA and dexmedetomidine in infants with a suspected NMD. 


\section{Abbreviations}

NMD: Neuromuscular disorder; GA: General anesthesia; RA: Regional anesthesia; SA: Spinal anesthesia

\section{Acknowledgements}

We would like to thank Editage (www.editage.com) for the English language editing of this manuscript.

\section{Authors' contributions}

$\mathrm{YI}$ was the main author of this manuscript. $\mathrm{YI}$ and MM participated in anesthetic management. YI and TS contributed to the data collection. AT and MM supervised the manuscript drafting. All authors read and approved the final manuscript.

\section{Funding}

Not applicable.

\section{Availability of data and materials}

Not applicable.

\section{Ethics approval and consent to participate}

The current study was approved by our Institutional Research Ethics Board at Anjo Kosei Hospital.

\section{Consent for publication}

Written informed consent was obtained from the patient's parent.

\section{Competing interests}

The authors declare that they have no competing interests.

Received: 21 August 2020 Revised: 8 October 2020

Accepted: 12 October 2020 Published online: 19 October 2020

\section{References}

1. Shapiro F, Athiraman U, Clendenin DJ, Hoagland M, Sethna NF. Anesthetic management of 877 pediatric patients undergoing muscle biopsy for neuromuscular disorders: a 20-year review. Paediatr Anaesth. 2016:26:71021.

2. Whitaker EE, Wiemann BZ, DaJusta DG, Alpert SA, Ching CB, McLeod DJ, et al. Spinal anesthesia for pediatric urological surgery: reducing the theoretic neurotoxic effects of general anesthesia. J Pediatr Urol. 2017;13: 396-400.

3. Kachko L, Simhi E, Tzeitlin E, Efrat R, Tarabikin E, Peled E, et al. Spinal anesthesia in neonates and infants - a single-center experience of 505 cases. Paediatr Anaesth. 2007;17:647-53.

4. Verma D, Naithani U, Gokula C, Harsha. Spinal anesthesia in infants and children: a one year prospective audit. Anesth Essays Res. 2014:8:324-9.

5. Ing C, Sun LS, Friend AF, Roh A, Lei S, Andrews $H$, et al. Adverse events and resource utilization after spinal and general anesthesia in infants undergoing pyloromyotomy. Reg Anesth Pain Med. 2016:41:532-7.

6. Frawley G, Bell G, Disma N, Withington DE, de Graaff JC, Morton NS, et al. Predictors of failure of awake regional anesthesia for neonatal hernia repair: data from the general anesthesia compared to spinal anesthesia (GAS) study: comparing apnea and neurodevelopmental outcomes. Anesthesiology. 2015:123:55-65.

7. Williams RK, Adams DC, Aladjem EV, Kreutz JM, Sartorelli KH, Vane DW, et al. The safety and efficacy of spinal anesthesia for surgery in infants: the Vermont Infant Spinal Registry. Anesth Analg. 2006;102:67-71.

8. Pepper MB, Njathi-Ori C, Kinney MO. Don't stress: a case report of regional anesthesia as the primary anesthetic for gynecologic surgery in a patient with mitochondrial myopathy and possible malignant hyperthermia susceptibility. BMC Anesthesiol. 2019;19:226.

9. Racca F, Mongini T, Wolfler A, Vianello A, Cutrera R, Del Sorbo L, et al. Recommendations for anesthesia and perioperative management of patients with neuromuscular disorders. Minerva Anestesiol. 2013;79:419-33.

10. Bong CL, Yeo AS, Fabila T, Tan JS. A pilot study of dexmedetomidine sedation and caudal anesthesia for inguinal hernia repair in infants. Paediatr Anaesth. 2016:26:621-7.

11. Somri M, Gaitini L, Vaida S, Collins G, Sabo E, Mogilner G. Postoperative outcome in high-risk infants undergoing herniorrhaphy: comparison between spinal and general anaesthesia. Anaesthesia. 1998;53(8):762-6.

\section{Publisher's Note}

Springer Nature remains neutral with regard to jurisdictional claims in published maps and institutional affiliations.

\section{Submit your manuscript to a SpringerOpen ${ }^{\circ}$ journal and benefit from:}

- Convenient online submission

- Rigorous peer review

- Open access: articles freely available online

High visibility within the field

- Retaining the copyright to your article

Submit your next manuscript at $\boldsymbol{\nabla}$ springeropen.com 